\title{
Biomimetic remineralizing agents influence the wettability of artificial caries-affected dentin surface after dentin acid etching
}

\section{Danilo Martho*, Luiz Filipe Barbosa-Martins, Jossaria Pereira de Sousa, Regina Maria Puppin-Rontani.}

\section{Abstract}

This study evaluated the influence of wettability of remineralizing treatment using $0.2 \%$ Sodium Fluoride (NaF); MI Paste ${ }^{\mathrm{TM}}$ (MP) and Curodont ${ }^{\mathrm{TM}}$ Repair (CR) on demineralized dentin (DD) obtained by a biological model, after etching in the bonding process. Bovine dentin blocks were divided into five groups: G1- Sound Dentin; G2-DD; G3-DD + NaF; G4-DD + MP and G5-DD + CR. The surface of G2, G3, G4 and G5 were demineralized by biological model (S. mutans biofilm), the softener dentin was removed by grinding and polishing and, then, treated as groups. Wettability was measured by the contact angle between the water and the dentin: 1.After remineralizing agents applying; 2.Prior acid etching; and 3.After acid etching 15s; and also between Adper ${ }^{\mathrm{TM}}$ Single Bond 2 adhesive (SB) and dentin, after acid etching, using sessile drop method. The treatment with MP and CR showed smaller values of contact angle, thereby improving wettability. MP or CR associated with SB is the best indication for wettability improvement of demineralized dentin surface.

Key words: Demineralized dentin, remineralization, wettability

\section{Introduction}

It is known that the penetration of the adhesive to dentin is one of the most important physical features for adhesion (1), and is directly related to wetting of dentin. Ricci et al., 2014 (2), noticed that wettability of the caries-affected dentin is higher than that of sound dentin. The reinforcement and restructuring of demineralized dentin through remineralizing agents could favor the improvement of demineralized dentin surface properties. The aim of this study was to evaluate the influence of remineralizing systems applying on demineralized dentin produced by $S$. mutans biofilm, similar to caries-affected dentin on the physical property of wettability of the dentin before and after conditioning with $37 \%$ phosphoric acid, simulating bonding procedures, with different remineralizing agents $(0.2 \%$ sodium fluoride - NaF (NF), MI Paste $^{\mathrm{TM}}$ (MP) and Curodont ${ }^{\mathrm{TM}}$ Repair (CR).

\section{Results and Discussion}

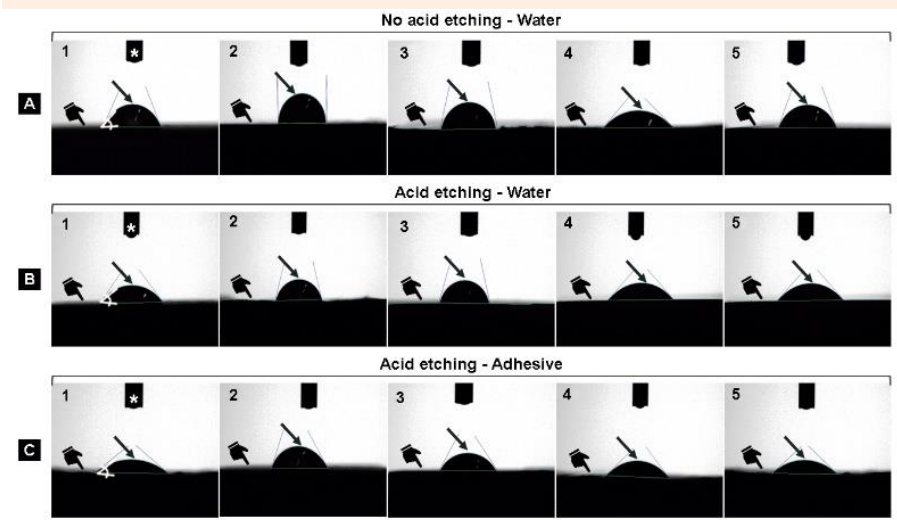

Figure 1. Representative images of dentin surfaces. 1-Sound Dentin; 2-Demineralized Dentin by biological model (DDB); 3-DDB+NaF; 4-DDB+MP Paste ${ }^{\mathrm{TM}}$; 5-DDB+Curodont ${ }^{\mathrm{TM}}$ Repair Pointer - dentin surface; Arrow - drop of water; * dispenser syringe type; $\mathbf{Z}$ - contact angle.

The demineralized dentin when treated with MP (Figure 1 - A4, B4 and C4), CR (Figure 1 - A5, B5 and C5) and sound dentin (Figure 1 - A1, B1 and C1) showed lower contact angles, providing significantly lower hydrophobicity substrate $(\mathrm{p}<0.05)$ and increased wettability, respectively. The demineralized dentin treated with $\mathrm{CR}$ showed a similar behavior to the sound dentin with and without conditioning ( $\mathrm{p}>0.05)$. However, NaF (Figure 1 A3, B3 and C3) did not show statistically significant differences than demineralized dentin ( $p>0.05)$ (Figure 1 - A2, B2 and C2) showing an increased hydrophobicity on surface, consequently, lower wettability. The same happened after phosphoric acid etching, simulating the bonding procedure; the contact angle values decreased for all groups $(\mathrm{p}<0.001)$, except for the MP group ( $>>0.05)$, demonstrating a more hydrophilic surface (Table 1 and Table 2).
Table 1. Contact angles between the water drop and sound and cariesaffected dentin surfaces treated with different remineralizing agents

\begin{tabular}{lll}
\hline \multirow{2}{*}{ Groups } & \multicolumn{2}{c}{ Type of Dentin Substrate } \\
\cline { 2 - 3 } & \multicolumn{1}{c}{ No acid etching } & Acid etching \\
\hline SD & $67.11 \pm 6.36 \mathbf{b}$ & $44.91 \pm 3.01 \mathbf{a *}$ \\
DDB & $85.85 \pm 4.46 \mathbf{A b}$ & $55.38 \pm 6.85 \mathbf{A a}^{*}$ \\
DDB + NaF & $78.20 \pm 9.21 \mathbf{A b}$ & $52.85 \pm 3.16 \mathbf{A a}^{*}$ \\
DDB + MP & $36.11 \pm 6.69 \mathbf{C a}$ & $34.40 \pm 3.82 \mathbf{C a}$ \\
DDB + CR & $67.82 \pm 5.55 \mathbf{B b}$ & $44.52 \pm 3.34 \mathbf{B a}$ \\
\hline
\end{tabular}

Lowercase letters compare means in the rows by $\mathrm{t}$ test $(\mathrm{p}<0.001)$ and uppercase letters compare means in the columns by oneway ANOVA and Tukey test $(\mathrm{p}<0.05)$. * indicates statistically significant difference $(\mathrm{p}<0.05)$ by Dunnett test. Means followed by same letters do not differ significantly $(\mathrm{p}>0.05)$.

Table 2. Contact angles between the adhesive Adper ${ }^{\mathrm{TM}}$ Single Bond 2 drop and sound and caries-affected dentin treated with different remineralizing agents.

\begin{tabular}{lc}
\hline \multirow{2}{*}{ Groups } & Type of Dentin Substrate \\
\cline { 2 - 2 } \multicolumn{1}{c}{ Acid etching } \\
\hline SD & $35.07 \pm 2.66^{*}$ \\
DDB & $50.67 \pm 5.90 \mathbf{A}^{*}$ \\
DDB + NaF & $45.93 \pm 5.87 \mathbf{A}^{*}$ \\
DDB + MP & $38.15 \pm 3.81 \mathbf{B}$ \\
DDB + CR & $38.88 \pm 6.59 \mathbf{~ B}$ \\
\hline
\end{tabular}

Uppercase letters compare means in the columns by one-way ANOVA and Tukey test $(\mathrm{p}<0.05)$. * indicates statistically significant difference with the control group (sound dentin) $(\mathrm{p}<0.05)$ by Dunnett test. Means followed by same letters do no differ significantly $(\mathrm{p}>0.05)$.

The results of this study can be attributed to the presence of mineral crystallites in the collagen matrix after remineralization, which may have contributed to decrease the values of contact angles (3), since a positive correlation between the surface level of mineral and the liquid spreading capacity has been demonstrated by Panighi \& G'Sell (4).

\section{Conclusions}

The use of CR or MP remineralization systems is a good approach when SB is used to bonding on demineralized dentin surface.

\section{Acknowledgement}

Authors are grateful to PIBIC and $\mathrm{CNPq}$ by initiation scholarship and the Credentis to supply the Curodont ${ }^{\mathrm{TM}}$ Repair.

Nakabayashi N, Pashley D. Hybridization of Dental Hard Tissues. Chicago Quintessence. 1998;127.

Ricci HA, Scheffel DLS, De Souza Costa CA, Dos Santos FJ, Jafelicci J, Hebling J. Wettability of chlorhexidine treated non-carious and caries-affected dentine. Aust Dent J. 2014;59(1):37-42.

Bertassoni LE, Habelitz S, Pugach M, Soares PC, Marshall SJ, Marshall GW. Evaluation of surface structural and mechanical changes following remineralization of dentin. Scanning. 2010;32(5):312-9.

Panighi M, G'Sell C. Influence of calcium concentration on the dentin wettability by an adhesive. J Biomed Mater Res. 1992;26:1081-9. 